\title{
LA FUERZA DE LA SANGRE, LA ILUSTRE FREGONA Y LAS DOS DONCELLAS: ¿TRES TIPOS FOLCLÓRICOS?
}

\author{
PierRe DARNis \\ Université Bordeaux Montaigne \\ pierre.darnis@u-bordeaux-montaigne.fr
}

\begin{abstract}
12 esulta siempre complejo estudiar el cuento oral maravilloso. Se suele recurrir a estructuras generales como el tipo de Aarne-Thompson-Üther ${ }^{1}$ la impresión de estabilidad que ofrecen puede engañarnos. Paulme (1976: 23), por ejemplo, critica la cadena de funciones de la morfología proppiana:
\end{abstract}

1. L’ordre dans lequel se suivent les séquences n’est pas nécessairement immuable : ainsi la rencontre d'un médiateur n'est pas indispensable ; elle a lieu, elle se fait aussi bien avant qu'après l'énoncé d'une épreuve qui peut elle-même avoir DISPARU $[\ldots]$.

2. Il arrive qu'une séquence élémentaire, sinon plusieurs, se gonfle jusqu'à former une histoire indépendante à l'intérieur de la narration. Ces récits dans le récit (ce sera par exemple celui des différentes tâches que le héros se voit imposer) obéissent eux-mêmes à certains arrangements qui ne sont pas en nombre illimité, mais forment des sortent de moules où se coule la narration.

De la misma manera, Lévi-Strauss (1906: 310) apuntaba que se daban auténticas inversiones cuando se transforma un mito en cuento: «au lieu de vieux, le héros est jeune [...]; au lieu d'une histoire inspirée par une notion de justice distributive [...], la marche [de l'intrigue] conduit à une issue tragique et inéluctable». Eso sin contar que el cuento folclórico es mucho menos rígido en su «coherencia lógica» que el mito: las consejas ofrecen más posibilidades de juego; «les

1 Piénsese en los tipos 300-749 de la clasificación de Aarne y Thompson (1964), modernizadas por Üther (2004). En adelante: ATU 300-749. 
permutations y deviennent relativement libres et elles acquièrent progressivement un certain arbitraire» (154).

La influencia del formalismo, el apego a las regularidades «científicas» y la celebridad de los relatos impresos de Straparola y Perrault tienden a hacernos pensar que el cuento de literatura oral es un corpus, y por analogía un cuerpo que puede someterse a un análisis anatómico. Pero el cuento no es un objeto sino una práctica; es un arte que se plasma en una performance y que permite al cuentista disolver y desestructurar con relativa libertad los tipos y jugar con los motivos de todo el repertorio folclórico (Holbek 1990). Por ello, para señalar la deuda cervantina con el cuento maravilloso, preferí insistir ante todo (Darnis 2006: 252-284) en la importancia de los motivos folclóricos dentro de las Novelas ejemplares².

En el trabajo que afronto ahora, convendría sin embargo recordar que, dentro de las técnicas del contar folclórico, la memorización de una serie de tramas forma parte de las competencias básicas del cuentista. Por muy imperfecto que parezca el concepto de tipo si lo usamos de forma rígida, aquellos patrones narrativos legados por el pasado humano constituyen soportes narrativos esenciales durante la performance del cuentista. El contar se caracteriza por una cierta estabilidad narrativa; si los oyentes no perciben las semejanzas entre varias historias folclóricas, el cuentista sí sabe adaptar perfectamente antiguas tramas a ambientes y contextos nuevos.

En el caso cervantino, si como asegura el cura Pero Pérez (DQ I, 42), el relato de Ruy Pérez parece ser una «conseja de aquellas que las viejas cuentan el invierno al fuego», la crítica contemporánea pudo demostrar que esta correspondencia intuitiva responde a una realidad narrativa. Como buen cuentista (Moner 1989), Cervantes recogió el tipo de la Hija del diablo (ATU 313) para estructurar la historia del capitán cautivo. La relativa verosimilitud del caso (el agresor tiene los rasgos generosos de Agi Morato), así como la individualización de los personajes (el príncipe azul es ahora un español leonés de noble ascendencia), no hacen desaparecer la estructura del viejo patrón maravilloso (Oliver Asín 1948; Delpech 1981; Chevalier 1983). Pese al concienzudo trabajo de reelaboración narrativa del repertorio folclórico oral, podemos pues preguntarnos si, en sus Novelas ejemplares, Cervantes no siguió también con fidelidad algunos tipos (o tramas) tradicionales.

Cuando nos fijamos en la recepción de sus contemporáneos, no podemos menos que constatar que la materia novelesca que Cervantes cubrió con un barniz mimético y verosímil ha saltado a la vista de un profesional tan agudo y calificado como Lope de Vega:

En tiempo menos discreto que el de agora, aunque de más hombres sabios, llamaban a las novelas cuentos. Estos se sabían de memoria, y nunca, que yo me acuerde, los vi escritos, porque se reducían sus fábulas a una manera de libros que

2 Las referencias al texto de las Novelas ejemplares remiten a la edición de García López (2001). 
parecían historias, y se llamaban en lenguaje puro castellano caballerías, como si dijésemos hechos grandes de caballeros valerosos (Vega 2002: 104).

En este breve artículo, quisiera seguir la pista de esta rápida interpretación sobre las Novelas ejemplares. Si el arte narrativo de Cervantes no descansa únicamente en la presencia de tal o cual motivo folclórico, sino que más bien reutiliza viejas consejas del patrimonio popular, Lope habría metido el dedo en la llaga al rebajar el orgullo de Cervantes («yo soy el primero que ha novelado en lengua española»). En las Ejemplares, tres novelas (por lo menos) proceden del repertorio de los cuentos de hadas: La fuerza de la sangre, Las dos doncellas y La ilustre fregona $^{3}$. ¿Qué deben estos relatos a la biblioteca oral de los cuentistas? ¿Podemos asociar cada uno de los tres a un cuento tradicional?

Veremos que tanto la Novela de la fuerza de la sangre como la de La ilustre fregona tienen obvias afinidades con dos arquetipos narrativos del folclore maravilloso, pero este parentesco nuclear entraña otros, menos evidentes, y reveladores de la pasión cervantina por el imaginario folclórico.

\section{LA FUERZA DE LA SANGRE, LAS DOS DONCELLAS Y EL TIPO (ATU) 425}

El difícil reconocimiento del origen tradicional de La fuerza de la sangre y Las dos doncellas se debe a una astucia: Cervantes dividió la trama original en dos historias separadas.

Cuando asociamos estas dos novelas cortas, constatamos que vuelven a formar una macrosecuencia conocida:

1 - Una joven seducida / raptada por un ser monstruoso.

2 - Pérdida del amante.

3 - Búsqueda del amante.

4 - Recuperación del amante.

5 - El amante pierde su apariencia monstruosa.

3 En Lecture et initiation dans le récit bref cervantin (Darnis 2006: 285-286), quise llamar la atención también sobre el cuento de los dos amigos: «Dans La Galathée, le premier 'roman' de Cervantès, on pouvait apercevoir à travers le récit de Timbrio et Silerio une anomalie dans l'ensemble des narrations enchâssées, marquées par une fin triste, à la manière des narrations de M. Bandello. Le récit est porté par une structure ascendante, mais l'amour, principal sujet du conte merveilleux, n'est pas le centre d'attention de cette histoire, plutôt axée sur la parfaite fidélité entre deux amis». «Juan Bautista Avalle-Arce a ainsi suivi les métamorphoses du conte des deux amis. Mais la démarche reste périlleuse. Conclure que le Curioso impertinente entretient des relations d'intertextualité avec la formule narrative des Deux amis ne signifie pas qu'il en fait partie. De plus, quoique le conte des deux amis ait une source orale et circule dans le répertoire des conteurs populaires, il reste difficilement rattachable au monde de la féerie. St. Thompson ne voit d'ailleurs dans cette histoire qu'un motif périphérique (H 1558.1; Rotunda 1973)».

Edad de Oro, XXXIII (2014), pp. 151-162, ISSN: 0212-0429 
Se reconoce la morfología narrativa del cuento (ATU) 425. La historia de $L a$ Bella y la Bestia ha sido canonizada por la adaptación literaria de Madame de Villeneuve y, luego, de Marie Leprince de Beaumont en el siglo XVIII (respectivamente 1740 y 1757)4. En Italia, G. Basile (Lo cunto de li cunti, 1634-1636) había ofrecido años antes una versión literaria de ese viejo relato folclórico (II, 9), pero ya en el siglo Xvi se puede rastrear la historia de La Bella y la Bestia, puesto que también se leía en el «mito» de Cupido y Psique. Trama famosa recordada por Boccaccio en su Genealogia deorum gentilium, la búsqueda de «Amor» por Psique había ocupado la parte central del Asno de Oro de Apuleyo y de sus adaptaciones modernas (cf. los cap. IV, 5-VI, 3 en el texto de Cortegana).

En la Novela de la fuerza de la sangre, Cervantes trae de forma bastante rigurosa el patrón narrativo que estructura el tipo 425. La novela recoge de entrada el nudo que abre la historia de Cupido y Psique: el rapto de Leocadia es el equivalente novelesco del motivo R $11.1^{5}$. En este contexto simbólico que asocia un monstruo con una joven, la violación no supone una innovación destinada a verosimilizar el sustrato folclórico; se integra al contrario a la perfección dentro del imaginario de la depredación. Cervantes precisa que fue metafóricamente por un lobo como fue raptada Leocadia:

Encontráronse los dos escuadrones: el de las ovejas con el de los lobos [...]. Arremetió Rodolfo con Leocadia, y, cogiéndola en brazos, dio a huir con ella; la cual no tuvo fuerzas para defenderse y el sobresalto le quitó la voz para quejarse, y aun la luz de los ojos, pues, desmayada y sin sentido, ni vio quién la llevaba, ni adónde la llevaban (FS, 304).

La agresión sexual de que será objeto Leocadia aparece así como la consecuencia lógica de aquel primer ataque salvaje y animal: «Ciego de la luz del entendimiento, a escuras robó la mejor prenda de Leocadia» (FS, 306) ${ }^{6}$.

También asociada con la primera etapa del tipo, destaca en la novelita la importancia de la figura paterna. En la versión cervantina, ni aparece el oráculo de Apuleyo (IV, 5), ni hay referencia alguna a la deuda del padre con la Bestia porque le hubiera robado una rosa (motivo S 240.1 de la hija concedida en «La Belle et la Bête»). En la novela cervantina, la ambientación mimética va a imponer

4 «Type 425C is caracterized by the "presents for the daughters" introduction and the absence of a quest or search» (Uther 2004: 252).

Sobre el dragón raptor: Propp (1983: 286-287, 324-334).

6 En la historia de Amor y Psique (como en La fuerza de la sangre), el simbolismo erótico del rapto se explicita en la secuencia siguiente: «después de haber pasado un rato de la noche comenzó a dormir y luego despertó con gran miedo y espanto temiendo en tanta soledad no le aconteciese ningún daño a su virginidad; de lo cual ella tanto mayor tenía cuanto más estaba ignorante de lo que allí había sin ver ni conocer a nadie. Estando en este medio vino el marido no conocido y subiendo en la cama hizo su mujer a Psiches, y antes que fuese el día partiose de allí» (Apuleyo 1543, V, 1). 
unas relaciones de fuerza entre «un anciano hidalgo» y un «caballero» de «hasta veinte y dos años» (FS, 303-304). Pero en este particular, se nota que la novela ejemplar no se aparta de su fuente y conserva la disimetría social que se observa en la versión clásica (humanidad de Psique / divinidad) o en las futuras versiones francesas (mercader / noble).

En la Novela de las dos doncellas, encontramos las mismas analogías. Como Leocadia, Teodosia tiene un padre y, si bien no asoma más que al final, resulta fundamental para el desenlace $(D D, 479)$. Del mismo modo, en este relato también aflora la temática del rapto, aunque de forma simbólica. Así relata Teodosia por qué no pudo resistir la embestida verbal del caballero:

cada palabra era un tiro de artillería que derribaba parte de la fortaleza de mi honra; cada lágrima era un fuego en que se abrasaba mi honestidad; cada suspiro, un furioso viento que el incendio aumentaba, de tal suerte que acabó de consumir la virtud que hasta entonces aún no había sido tocada; $y$, finalmente, con la promesa de ser mi esposo, a pesar de sus padres, que para otra le guardaban, di con todo mi recogimiento en tierra $(D D, 448)^{7}$.

Pero la secuencia del rapto no es más que el preludio de un destino maravilloso. Para comprender la relación entre La fuerza de la sangre y el relato maravilloso de La Bella y la Bestia, un momento particularmente significativo es el de la segunda etapa narrativa, la de la «pérdida del amante».

En la historia de Leocadia (FS), el despertar permite descubrir un suntuoso y desconocido palacio:

Halló la puerta, pero bien cerrada, y topó una ventana que pudo abrir, por donde entró el resplandor de la luna, tan claro, que pudo distinguir Leocadia las colores de unos damascos que el aposento adornaban. Vio que era dorada la cama, y tan ricamente compuesta que más parecía lecho de príncipe que de algún particular caballero. Contó las sillas y los escritorios; notó la parte donde la puerta estaba, y, aunque vio pendientes de las paredes algunas tablas, no pudo alcanzar a ver las pinturas que contenían. La ventana era grande, guarnecida y guardada de una gruesa reja; la vista caía a un jardín que también se cerraba con paredes altas; dificultades que se opusieron a la intención que de arrojarse a la calle tenía. Todo lo que vio y notó de la capacidad y ricos adornos de aquella estancia le dio a entender que el dueño della debía de ser hombre principal y rico, y no comoquiera, sino aventajadamente (FS, 309).

\footnotetext{
7 Recuérdese que el «viento» es una representación tradicional del amor y de la sexualidad masculina (Durand 1992: 199). Véase Apuleyo (1543: IV, 5): «Estando Psiches muy temerosa llorando encima de aquella peña, vino un manso viento de cierzo y, como quien extiende las alas, la tomó en su regazo».
} 
La descripción es similar a lo que podemos leer en otros relatos influenciados por el folclore (Apuleyo 1543: V, 1). La Bella se extraña de estar sola en medio del palacio y tiene la impresión de situarse en un lugar que le impide recogerse a casa («Sintió Leocadia que quedaba sola y encerrada», FS, 308) ${ }^{8}$.

A este respecto, sin embargo, la novela dista de parecerse al cuento francés, donde la separación con el progenitor explica la tristeza de la Bella. Con todo, Cervantes dota a su texto de motivos que entroncan con la cuentística: como en Amor y Psique, el agresor de Leocadia desaparece porque no quiere ser reconocido («ya él se había puesto en parte donde no pudiese ser visto [...]. Rodolfo, en tanto, vuelto a su casa, [...] se partió a Italia» (FS, 310-311); además la deja encinta:

a pocos meses vio serle forzoso hacer por fuerza lo que hasta allí de grado hacía. Vio que le convenía vivir retirada y escondida, porque se sintió preñada: suceso por el cual las en algún tanto olvidadas lágrimas volvieron a sus ojos, y los suspiros y lamentos comenzaron de nuevo a herir los vientos, sin ser parte la discreción de su buena madre a consolalla. Voló el tiempo, y llegose el punto del parto, y con tanto secreto, que aun no se osó fiar de la partera; usurpando este oficio la madre, dio a la luz del mundo un niño de los hermosos que pudieran imaginarse (FS, 312) .

Podríamos pensar que la particularidad de la novela, en esta etapa del relato, estriba en que Rodolfo permite a Leocadia volver a casa de sus padres. En el cuento de Apuleyo, por ejemplo, Psique rompe la monotonía de su vida en el palacio pidiendo a sus hermanas que se reúnan con ella. Es difícil saber si, en las distintas versiones que circulaban entonces, la vuelta a casa formaba parte de los motivos posibles; sea lo que fuere, podemos recordar que en la historia de Madame Leprince de Beaumont, la «Belle», con su insoportable tristeza, consigue convencer a la «Bête» de que necesita pasar algunos días junto con su padre, lejos del palacio. En todo caso, Cervantes no se aleja de la versión tradicional cuando escribe que Rodolfo la deja sola después de haber salido los dos del palacio. La historia clásica contaba lo mismo: Psique, colgada del pie de Cupido, volaba con él hasta que «cayó en el suelo»; enojado por el descubrimiento de Psique, Cupido decidió huir y «levantose con sus alas y voló en alto hacia el cielo» (V, 4).

La etapa siguiente del tipo folclórico - la tercera - es la de la «búsqueda del amante» (motivo H 1125/Q 505.2). En La fuerza de la sangre, Cervantes concentra la acción y no permite que Leocadia, embarazada, salga de la casa familiar

8 Apuleyo (1543: V, 1): «todo aquel día la mezquina consumió en llantos y en lágrimas diciendo muchas veces que ahora conocía que era muerta y perdida por estar encerrada y guardada en una cárcel honesta apartada de toda habla y conversación humana». Véase también el cuento de «La Belle et la Bête» en Si les fées m'étaient contées... (Lacassi, ed. 2003: 960).

9 Apuleyo (1543: V, 2): «acrecentaremos nuestro linaje que aun este tu vientre niño otro niño trae ya dentro; y si tu encubrieres este secreto, yo te digo que será divino». 
( «Ella, en este entretanto, pasaba la vida en casa de sus padres con el recogimiento posible, sin dejar verse de persona alguna, temerosa que su desgracia se la habían de leer en la frente», FS, 312). Sin embargo, la secuencia tradicional no desaparece del todo. Podemos imaginar incluso que Cervantes quiso aprovechar su extraordinaria potencialidad novelesca y que la Novela de las dos doncellas fue el fruto de la independización de la tercera etapa del cuento tradicional.

La historia de Teodosia comienza precisamente cuando la joven inicia su búsqueda (versión 425G del tipo) ${ }^{10}$. Cervantes, como si quisiera llamar la atención de sus lectores sobre la homología entre Las dos doncellas y La fuerza de la sangre, introduce una falsa heroína de nombre muy sugerente, Leocadia, que va a perturbar la progresión de la protagonista ${ }^{11}$. Teodosia y Leocadia no conocen la vergüenza de la maternidad sin marido, pero repiten la prueba del viaje que caracteriza la experiencia de Psique.

En La fuerza de la sangre, erraríamos si pensáramos que Cervantes limita la influencia del tipo tradicional al principio del relato. Muy pronto, percibimos que surgen otras improntas. A partir del atropello de «Lusico», Cervantes conserva en efecto el protagonismo de la «mala madre», que constituía un pilar recurrente en los cuentos maravillosos, ya se trate de Venus en Amor y Psique (Apuleyo), ya de la «vieja» en La falsa novia toma el puesto de la heroína (Chevalier, Camarena 1995). La especificidad de la versión cervantina se cifra en la transformación del carácter de la «vieja», que, en la novelita, pierde su maldad (motivo N 825.3) ${ }^{12}$. Pero, sobre este particular, también la singularidad cervantina tiene antecedentes famosos. Doña Estefanía parece recuperar la función mediadora de donante y auxiliar que poseen tantas madres en las consejas de la literatura oral (Darnis 2006: 363) ${ }^{13}$. Así,

10 En su antología, Chevalier y Camarena (1995: 459-465) traen una versión similar.

11 Darnis (2006: 289-290): «À ce stade du scénario, Las dos doncellas empruntent à la tradition orale. Alors que Teodosia recherche le ravisseur de sa vertu, elle retrouve cet amant inconstant quand celui-ci est sur le point de se marier avec une autre femme, en l'occurrence Leocadia. L'art cervantin a donc consisté à percevoir les possibilités narratives de ce motif (N 681.1) et à lui donner la consistance d'une véritable trame secondaire, en rapprochant Leocadia de la sphère d'action du Faux-héros».

12 Véase Apuleyo (1543: V, 1-3).

13 Véase el papel conciliador de Júpiter en Apuleyo (1543: V, 3): «Como quier que tú, señor hijo, nunca me guardaste la honra que se debe a los padres por mandamiento de los dioses; pero aun este mismo pecho, en el cual se encierran y disponen todas las leyes de los elementos, y a las veces de las estrellas, muchas veces lo llagaste con continuos golpes del amor, y lo ensuciaste con muchos lazos de terrenal lujuria, y lisiaste mi honra y fama con adulterios torpes y sucios contra las leyes, especialmente contra la ley Julia, y a la pública disciplina, transformando mi cara y hermosura en serpientes, en fuegos, en bestias, en aves y en cualquier otro ganado. Pero, con todo esto, recordándome de mi mansedumbre y de que tú creciste entre estas mis manos, yo haré todo lo que tú quisieres, y tú sépaste guardar de otros que desean lo que tú deseas. Esto sea con una condición: que si tú sabes de alguna doncella hermosa en la tierra, que por este beneficio que de mí recibes debes de pagarme con ella la recompensa». 
la madre de Rodolfo, en vez de poner trabas a la reunión de los dos protagonistas, es quien facilita la vuelta de su hijo y su matrimonio con Leocadia (FS, 317-320).

En la parte final de la sexta y de la décima novela ejemplar, lo que distingue el lector es una evolución realmente maravillosa. A imagen de lo que ocurre en la mayoría de las versiones populares, el héroe cervantino pierde su naturaleza monstruosa. En Las dos doncellas, la agonía de Marco Antonio en Barcelona anticipa la de la Bestia en el jardín ${ }^{14}$ e imita el dolor de Cupido ${ }^{15}$. Pero tanto él $(D D, 472)$ como Rodolfo $(F S, 321)$ van a inquietar a sus prójimos y a sus amadas cuando desfallecen. En el folclore maravilloso, el motivo del desvanecimiento es esencial. Sirve para plasmar una ruptura psicológica e iniciática. Los oyentes pueden intuir así que el protagonista masculino ha dejado de ser un «lobo» cuando recobra el sentido; bastaba con adaptar el tópico del desencantamiento, tan frecuente en la literatura oral y concretado a veces por un simbólico beso (motivo D 700-799) ${ }^{16}$.

\section{LA NOVELA DE LA ILUSTRE FREGONA Y EL TIPO (ATU) 510}

La octava novela de la colección ejemplar es interesante desde un punto de vista folclórico porque su patrón «tipológico» es al mismo tiempo más evidente y menos monolítico que en La fuerza de la sangre.

Los indicios de su origen folclórico se corresponden con los siguientes motivos:

- la figura socialmente humilde de la fregona (IF, 384, 399; motivo L 102);

- la moza no sale de la «gran casa» (IF, 402; motivo de la reclusión L 131);

- Costanza no es la hija biológica de la mujer que la mantiene (IF, 425; motivo L 55);

- su padre biológico es un hombre lascivo (IF, 434-435; motivo T 44.1);

- la fregona tiene padrinos que la protegen (IF, 415, 429, 438; F 3311.117);

- el tabú del baile (IF, 402; motivo C 761.3) ${ }^{18}$;

4 Si les fées m'étaient contées... (Lacassin, ed. 2003: 964).

15 Apuleyo (1543: V, 3): «Cupido estaba malo de una grave llaga de fuego que le daba mucho dolor, llorando y en mucha duda de su salud».

16 Como apunta Souiller (2004: 195) «[on] s’évanouit beaucoup dans les nouvelles exemplaires, au point que l'on peut juger qu'il s'agit désormais d'une simple convention pour exprimer un excès d'émotion». Recuerdo en mi Lecture et initiation dans le récit bref cervantin que «l'histoire de Leocadia et Rodolfo se nourrit d'autres composantes du folklore féerique, puisqu'elle intègre la dialectique de l'oubli et du souvenir chez le personnage masculin et celui du réveil par le baiser» (D 1978.5)» (FS, 312: «Rodolfo, en tanto, vuelto a su casa, echando menos la imagen del crucifijo, imaginó quién podía haberla llevado; pero no se le dio nada, y, como rico, no hizo cuenta dello, ni sus padres se la pidieron cuando de allí a tres días, que él se partió a Italia, entregó por cuenta a una camarera de su madre todo lo que en el aposento dejaba [...]. Finalmente, él se fue con tan poca memoria de lo que con Leocadia le había sucedido, como si nunca hubiera pasado»).

17 Sobre la evolución de dicho motivo en la historia (desde la loba de Remo y Rómulo hasta la figura de la Reina) véase Propp (1975: 106-111).

18 Sobre los significados del baile para las doncellas, dentro de la práctica cortesana: Desaive (2002: 336-339). 
- la humildad de la heroína llama la atención de todos (IF, 382-383; motivo H 151.5);

- la fregona no se parece a sus dos «hermanas» y el héroe se niega a asociarse con éstas (IF, 411, motivo K 2212.1);

- un objeto recurrente y mineral define de modo metonímico a la protagonista (es «guarda de la plata labrada», IF, 399, 425; «la pantoufle de verre», motivo F 823.2);

- el motivo de la llave (IF, 425; C 913);

- reconocimiento de la identidad biológica de la heroína (IF, 429; motivos H90H 110);

- la fregona se casa con su príncipe azul (IF, 438; motivo L 162).

La convergencia de estos motivos sugiere que Cervantes trasplantó un guion antiguo, el de Cenicienta, para configurar la historia de Costanza y Avendaño ${ }^{19}$. No se puede afirmar sin embargo que el tipo 510 define la novela ejemplar, como sí fue el caso de La gatta cenerentola de G. Basile (Lo cunto de li cunti, I, 6) o de Cendrillon de Charles Perrault (Contes du temps passé, 1697). Cervantes introdujo demasiadas modificaciones como para que no cambiase sustancialmente la trama popular.

En primer lugar, la historia de raigambre folclórica se integra en otra, la de Avendaño. El autor español da al recorrido amoroso del protagonista masculino un papel vertebrador dentro de la fábula. Subordinando la acción de Costanza a la de Tomás, Cervantes prefiere centrar la historia en torno a la rivalidad entre aquel y el hijo del Corregidor, que hace entonces de falso héroe.

Por otra parte, la estructura conflictiva que enfrenta normalmente a la heroína con su madrastra sufre aquí un importante proceso de reducción, y hasta de inversión, puesto que Cervantes hizo de la madre adoptiva de Costanza - la «huéspeda»- una madrina bondadosa.

Al lado de estas reconfiguraciones, Cervantes dispuso en el argumento principal otros motivos adyacentes que nimban a Costanza de maravilla folclórica:

- Costanza nace de una relación sexual no consentida que recuerda el cuento de la «bella durmiente» (IF, 435; motivo N 711.2 ${ }^{20}$ );

- el nacimiento de la heroína se asemeja al de Edipo (IF, 429; motivo del niño abandonado R $131^{21}$ );

- el mesón es una versión verosímil de la «gran casa», tradicional en numerosos cuentos maravillosos ${ }^{22}$, y Costanza toma el papel conocidísimo en la literatura oral de la «hermanita» en un mundo rodeado de hombres ${ }^{23}$;

19 Canavaggio (1997: 287) veía en Costanza una «Cendrillon castillane».

20 Este motivo fue documentado por Ramond (1983) que lo asociaba con el tipo 410 («La Belle au bois dormant», Perrault 1981: 135). Véase también «Sole, Luna e Talia» en Basile, Lo cunto de li cunti, VI, 5.

21 Véase, por ejemplo, el cuento del ave de la verdad (tipo 707) en las Piacevoli notti (Straparola 1999: 205-219, IV, 3).

22 Propp (1970: 189); Propp (1983, cap. IV: «La gran casa»).

23 Propp (1983: 155-160) cita el ejemplo de Psique. Véase El amante liberal, 143: «Ocho días estuvimos en la isla, guardándome los turcos el mismo respeto que si fuera su hermana, y aun más». 
- el mutismo de la heroína (IF, 412, 416; tabú del hablar, motivo C 400)²4;

- la reclusión en un cuarto prohibido (IF, 416; motivo C 611) ${ }^{25}$.

En resumidas cuentas, podemos afirmar que tres de las doce Novelas ejemplares son el resultado de un trabajo de adaptación novelesca de algunas consejas famosas de la literatura oral y escrita. Las novelas de La fuerza de la sangre y Las dos doncellas se hicieron teniendo como horizonte de escritura la(s) historia(s) tradicionales que se corresponden ahora con la trama de La Bella y la Bestia.

Por lo que se refiere a la Novela de la ilustre fregona, se trata, dentro de todas las Ejemplares, del relato más rico en materiales procedentes del folclore maravilloso, y eso, por mucho que lo haya dotado Cervantes de pinceladas picarescas y verosimilizadoras. Estructurado a partir del tipo 510, el cuento sobre Costanza y Avendaño es una buena muestra del talento de cuentista de Cervantes: no se contentó con la trama de Cenicienta, sino que la ha nutrido con una pléyade de motivos antiguos y de otras historias folclóricas, como las de La Bella durmiente (ATU 410) o de Los doce hermanos (ATU 451). A propósito de la heroína, podemos leer que «debajo de aquella rústica corteza, debe de estar encerrada y escondida alguna mina de gran valor»; a las claras, la Novela de la ilustre fregona debe parte de su dimensión fascinante a la materia antigua que oculta pero que, luego, aflora en sus lances más estratégicos.

Recibido: 16/09/2014

Aceptado: 15/10/2014

\section{OBRAS CITADAS}

Apuleyo (1543). El asno de oro corregido [por Cortegana]. Medina del Campo: Pedro de Castro, a costa de Juan de Espinosa.

Basile, Giambattista (1999). Lo cunto de li cunti. Circé: Garzanti Libri.

Belmont, Nicole (1986). Paroles païennes. Mythe et folklore des frères Grimm à P. Saintyves. París: Imago.

(1999). Poétique du conte: essai sur le conte de tradition orale. París: Gallimard. (1991). «La figure de la conteuse dans la tradition orale». En Olivier Piffault (ed.). Il était une fois... les contes de fées. París: Seuil, pp. 503-511.

(2002). «Silence, mutisme et discrétion: itinéraire structurant des figures féminines dans le conte». En André Petitat (ed.). Contes: l'universel et le singulier. Lausanne: Payot, 2002, pp. 177-186.

24 Recuérdense el Sendebar, el cuento «Li sette palommielle» (Basile, Lo cunto de li cunti, IV, 8), la «Histoire de Djoullanare de la Mer» (Les passions voyageuses), «Les sept corbeaux» y «Les douzefrères» de los hermanos Grimm (1976). El lector interesado puede encontrar análisis valiosos en Flahault (1988: 113-150), Calvetti (1995) y Belmont (2002).

25 Propp (1983: 181-187). Véanse por ejemplo «Le sette palommielle» (Basile, Lo cunto de li cunti, IV, 8); Perrault (1981: 150-151), Grimm (1976: 44). 
Cervantes, Miguel de (1998). Don Quijote. Francisco Rico (dir.). Barcelona: Instituto Cervantes / Crítica.

(2001). Novelas ejemplares. Jorge García López (ed.). Barcelona: Crítica.

Calvetti, Anselmo (1995). «La sposa muta in versioni della fiaba AT 451». Lares, 61 (3). Florencia: Leo Olschki, pp. 375-390.

CAnavaggio, Jean (1997). Cervantès. París: Fayard.

Chevalier, Maxime (1983). «El cautivo entre cuento y novela». Nueva Revista de Filología Hispánica, 32, pp. 403-411.

Chevalier, Maxime y Julio Camarena (1995). Catálogo tipológico del cuento folklórico español. Cuentos maravillosos. Madrid: Gredos, 1995.

DARNIS, Pierre (2006). Lecture et initiation dans le récit bref cervantin. Toulouse: FRAMESPA. http://tel.archives-ouvertes.fr/tel-00116592

DeLPECH, François (1981). «Les noces du chef et de l'étrangère». En Françoise Vigier (ed.), Communautés nationales et marginalité dans le monde ibérique et ibéro-américain. Tours: Publications de l’Université de Tours, pp. 25-48.

Desarve, Jean-Paul (2002). «Les ambiguïtés du discours littéraire». En Natalie Davis y Arlette Farge (eds.), Histoire des femmes en Occident. París: Perrin, pp. 336-339.

Durand, Gilbert (1992). Les structures anthropologiques de l'imaginaire. París: Dunod.

Flahault, François (1988). L’interprétation des contes. París: Denoël.

Grimm (1976). Contes. París: Gallimard.

Holbek, Bengt (1990). «Variation and tale-type». En Veronika Görög-Karady (ed.), D’un conte à l'autre. La variabilité dans la littérature orale. París: CNRS, pp. 471-486.

LÉvi-Strauss, Claude (1996). Anthropologie Structurale II. París: Plon.

Kawan, René (ed.) (1987). Mille et Une Nuits (Les).3. Les passions voyageuses. París: Phébus. Moner, Michel (1989). Cervantès conteur. Ecrits et paroles. Madrid: Casa de Velázquez.

Oliver Asín, Jaime (1948). «La hija de Agi Morato en la obra de Cervantes». Boletín de la Real Academia Española, 27, pp. 245-339.

Paulme, Denise (1976). La mère dévorante : essai sur la morphologie des contes africains. París: Gallimard.

Perrault, Charles (1981). Contes. París: Gallimard.

Prope, Vladimir (1970). Morphologie du conte. París: Seuil. (1975). Edipo alla luce del folclore. Turín: Einaudi.

(1983). Les racines historiques du conte merveilleux. París: Gallimard. (1990). La fiaba russa: lezioni inedite. Turín: Einaudi.

RAMOND, Michèle (1983). "YYo soy la ilustre fregona" o la simbolización de un delirio». En Lenguaje, ideología y organización textual en las Novelas ejemplares. MadridToulouse: Universidad Complutense - Université Toulouse-Le Mirail, pp. 179-190.

Rotunda, Dominic Peter (1973). Motif-index of the Italian Novella in Prose. New York: Hastell House Publisher.

Lacassin, Francis (ed.) (2003). Si les fées m'étaient contées... 140 contes de fées de Charles Perrault à Jean Cocteau. París: Omnibus.

Souiller, Didier (1988). La littérature baroque en Europe. París: Presses Universitaires de France.

Straparola, Giovan Francesco (1999). Les nuits facétieuses. París: José Corti. 
Uther, Hans-Jörg (2004). The Types of International Folktales. A classification and Bibliography: Based on the System of Antti Aarne and Stith Thompson. Part I: Animal Tales, Tales of Magic, Religious Tales and Realistic with an Introduction. Helsinki: Suomalainen Tiedeakatemia.

Vega, Lope de (2002). Novelas a Marcia Leonarda. Antonio Carreño (ed.). Madrid: Cátedra.

\section{LA FUERZA DE LA SANGRE, LA ILUSTRE FREGONA Y LAS DOS DONCELLAS: ¿TRES TIPOS FOLCLÓRICOS?}

REsumen: En este trabajo, se recuperan las fuentes estructurales de tres de las Novelas ejemplares para poner de relieve el trabajo cervantino de adaptación de algunas consejas famosas de la literatura oral y escrita. Las novelas de La fuerza de la sangre y Las dos doncellas se gestaron teniendo como horizonte de escritura la(s) historia(s) tradicionale(s) de La Bella y la Bestia. Por lo que se refiere a la Novela de la ilustre fregona, se trata, dentro del conjunto de las Ejemplares, del relato más rico en materiales procedentes del folclore maravilloso, y eso por mucho que Cervantes lo haya dotado de pinceladas picarescas y verosimilizadoras. Estructurado a partir de la trama del tipo 510, el cuento sobre Costanza y Avendaño es una buena muestra del talento de cuentista de Cervantes: no se contentó con la trama de Cenicienta, sino que la ha nutrido con una pléyade de motivos antiguos y de otras historias folclóricas, como las de La Bella durmiente (ATU 410) o la de Los doce hermanos (ATU 451).

Palabras Clave: Cervantes, Novelas ejemplares, La fuerza de la sangre, La ilustre fregona y Las dos doncellas, Conseja, Cuento maravilloso, Folclore, Cenicienta, La bella y la bestia.

LA FUERZA DE LA SANGRe, LA ILUSTRE FREGONA AND LAS DOS DONCELLAS:

\section{THREE FOLKLORIC CHARACTERS?}

ABSTRACT: This paper recuperates the structural sources of three Novelas ejemplares to highlight the work of Cervantes' novel adaptation of some famous oral and written fairytales. La fuerza de la sangre and Las dos doncellas were based on traditional stories of the Beauty and the Beast. Regarding to La ilustre fregona, this fiction is, in all Novelas ejemplares, the richest one in terms of fairy folklore, in spite of the picaresque and the verisimilitude form of the story. The tale about Costanza and Avendaño is a good example of the talented storyteller Cervantes: not content with the plot of Cinderella, he infuses his plot with a plethora of ancient motifs and other folk tales, like Sleeping Beauty (ATU 410) or The Twelve Brothers (ATU 451).

Keywords: Cervantes, Novelas ejemplares, La fuerza de la sangre, La ilustre fregona, Las dos doncellas, Fairytale, Fairy tales, Folklore, Cinderella, Beauty and the Beast, Sleeping Beauty. 
Evangelina Rodríguez Cuadros (Universitat de València)

Novela cortesana, novela barroca, novela corta: de la incertidumbre al canon .9

Mita Valvassori (Universidad de Los Lagos)

El modelo narrativo del Decamerón en la Edad de Oro: una vieja historia .21

Antonio Gargano (Università degli Studi di Napoli Federico II)

«Difficile est proprie communia dicere»: el género de la novella entre

Boccaccio y Cervantes

Guillermo Carrascón (Università degli Studi di Torino)

Apuntes para un estudio de la presencia de Bandello en la

novela corta del siglo XVII

Leonardo Coppola (Università degli Studi «G. d'Annunzio» di Chieti-Pescara)

La proyección de Straparola en la novela española del Siglo de Oro desde una perspectiva editorial

Mireia Aldomì García

Didactismo, género literario y lector en Giraldi Cinzio.

María Jesús Zamora (Universidad Autónoma de Madrid)

«...En tiempo menos discreto que el de agora, aunque de hombres más sabios, se

Ilamaban a las novelas cuentos». La novela corta y el cuento en el Siglo de Oro.....109

Marcial Rubio (Università degli Studi «G. d'Annunzio» di Chieti-Pescara)

La contribución de Cervantes a la novela barroca: la ejemplaridad. .125

PIERRe Darnis (Université Bordeaux Montaigne)

La fuerza de la sangre, La ilustre fregona $y$ Las dos doncellas: ¿tres tipos

folclóricos?

María Soledad ArRedondo (Universidad Complutense de Madrid)

De La gitanilla $a$ La sabia Flora malsabidilla. El género, el personaje

y el matrimonio

Antonella Gallo (Università degli Studi di Verona)

Fabulaciones en equívocos burlescos: la Chrónica del monstro imaginado (1615)

de Alonso de Ledesma y novela corta barroca

David GonZález Ramírez (Universidad de Málaga)

El filósofo del aldea (1625) de Baltasar Mateo Velázquez: recepción textual

e hipótesis autorial.

Jonathan BRAdBury (University of Exeter)

La narrativa breve en la miscelánea del siglo XVII 
Cristina Castillo Martínez (Universidad de Jaén)

«La fuente del desengaño»: de las Noches de invierno de Eslava a la Tercera

Diana de Tejeda.

María Zerari (Université Paris-Sorbonne, CLEA)

Furor in fabula: La cruel aragonesa de Castillo Solórzano (o de la dama monstruo).. 241

Giulia Giorgi (Università degli Studi di Ferrara)

Alonso de Castillo Solórzano reescritor de sí mismo: algunas notas sobre los

Escarmientos de amor moralizados y el Lisardo enamorado .257

Angela Fabris (Alpen-Adria-Universität Klagenfurt)

El diálogo con el público y los espacios reales y de maravilla en

Casos prodigiosos y cueva encantada de Juan de Piña .267

María Rocío LePe García (IES San Sebastián, Huelva)

La traducción inglesa de Hipólito y Aminta: una adaptación

con fines comerciales 281

Andrea Bresadola (Università degli Studi di Udine)

La novela española en la Italia del siglo XVII: el caso de Il Feniso

de Francisco de Quintana

José Teruel (Universidad Autónoma de Madrid)

El triunfo del Desengaño. Marco y desengaño postrero de la Parte segunda

del Sarao y entretenimiento honesto, de María de Zayas

Nieves Romero-Díaz (Mount Holyoke College)

Lecturas alternativas en la Novela del fin bueno en mal principio

de doña Ana Francisca Abarca de Bolea.

Shifra Armon (University of Florida)

Compromiso y distanciamiento en La Venus de Ferrara

de Mariana de Carvajal Saavedra

Mechthild Albert (Rheinische Friedrich-Wilhelms-Universität Bonn)

Las "noches": un subgénero novelístico en perspectiva comparada.... .365

Fernando Copello Jouanchin (Université du Maine, Le Mans)

El mueble en la novela corta del Siglo de Oro: algunas reflexiones

en torno a la cama

Ilaria Resta (Università del Salento):

De la novella al entremés pasando por la novela corta: reescrituras del cuento

La gara delle tre mogli del Cieco di Ferrara. 


\section{EDAD DE ORO}

Revista de Filología Hispánica XXXIII

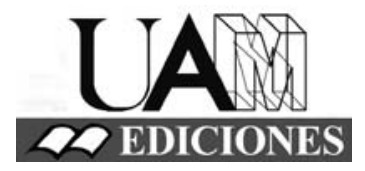




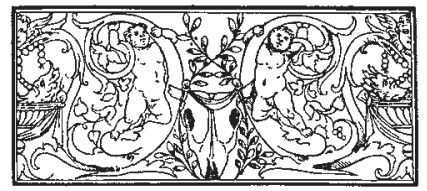

\section{Edad de Oro. Revista de Filología Hispánica}

ISSN: 0212-0429

Dirección:

Teodosio Fernández

Secretaría y edición:

José Ramón Trujillo

Coordinador del volumen XXXIII:

Rafael Bonilla Cerezo

Comité científico internacional:

Carlos Alvar (Univ. de Ginebra)

Ignacio Arellano (Univ. de Navarra)

Javier Blasco (Univ. de Valladolid)

Alberto Blecua (UAB)

Jean Canavaggio (Univ. de París X)

Laura Dolfi (Univ. de Turín)

Aurora Egido (Univ. de Zaragoza)

Víctor García de la Concha (RAE)

Luciano García Lorenzo (CSIC)

Joaquín González Cuenca (Univ. de Castilla-

La Mancha)

Agustín de La Granja (Univ. de Granada)

Begoña López Bueno (Univ. de Sevilla)

Michel Moner (Univ. de Toulouse III)

Joan Oleza (Univ. de Valencia)

Alfonso Rey (Univ. de Santiago)

Lina Rodríguez Cacho (Univ. de Salamanca)

Leonardo Romero Tobar (Univ. de Zaragoza)

Aldo Ruffinatto (Univ. de Turín)

Lía Schwartz (City University of New York)
Redacción y admisión de originales:

Teodosio Fernández

Edad de Oro

Departamento de Filología Española

Universidad Autónoma de Madrid

28049 Madrid (España)

Tfno.: +0034 914974090

correo: teodosio.fernandez@uam.es

Distribución, suscripción y venta:

Servicio de Publicaciones de la UAM

Universidad Autónoma de Madrid

28049 Madrid (España)

Intercambio de publicaciones:

Biblioteca de la Facultad de Filosofía y

Letras (UAM)

Universidad Autónoma de Madrid

28049 Madrid (España)

Han colaborado en este volumen:

Departamento de Filología Española (UAM)

Facultad de Filosofía y Letras (UAM)

Proyecto I+D FFI2013-41264-P La novela

corta del siglo XVII: estudio y edición (y II)

Edad de Oro se recoge en las siguientes bases de datos: SCOPUS, MLA Database, HLAS, Latindex, PIO-Periodical Content Index, ISOC, Dialnet, MIAR, ERIH, DICE, Sumaris CBUC, Ulrich's. Se encuentra evaluada en CIRC: A; INRECH: primer cuartil, posición 6 de 50; MIAR difusión ICDS live: 9.977; SCImago Journal \& Country Rank: H Index 2, SJR 0,101, Q4; RESH índice de impacto: 0.162; ERIH: A INT1; Carhus Plus+: B. 